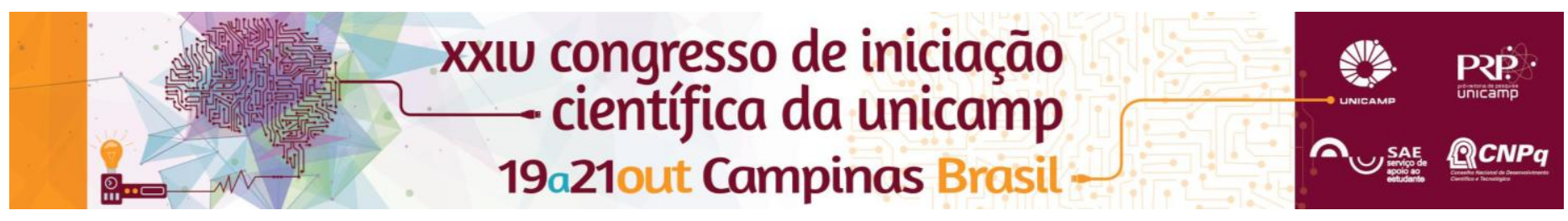

\title{
Análise das principais métricas utilizadas na avaliação da maturidade de projetos de manufatura enxuta
}

\author{
Vivien Cielusinsky*, Rosley Anholon.
}

\section{Resumo}

Este projeto de Iniciação Científica tem por objetivo identificar as principais métricas utilizadas para a avaliação da maturidade de projetos de manufatura enxuta, também conhecida pelo termo em inglês lean manufacturing. A filosofia lean foi desenvolvida no Japão há 45 anos e alterou significativamente todo o sistema produtivo mundial. Apesar dos excelentes resultados observados por meio da implantação desta filosofia em diferentes países, ainda é possível observar diferentes graus de maturação nas empresas, o que justifica o estudo das principais métricas utilizadas nesta análise.

\section{Palavras-chave:}

Lean Manufacturing, Métricas, Produção.

\section{Introdução}

O lean manufacturing é uma estratégia de produção que se iniciou no Japão no século XX, e, desde então, vendo sendo aplicada em diversos segmentos por todo o mundo. Seu principal objetivo é reduzir ao máximo os desperdícios, a fim de se obter o maior lucro possível.

Contudo, essa transição para os sistemas lean não é rápida e não produz todos os resultados esperados automaticamente, havendo barreiras que devem ser enfrentadas para atingir os objetivos. Dessa forma, as empresas não apresentam o mesmo grau de implantação lean, ou seja, algumas estão em um nível mais avançado do que outras.

O principal objetivo desse projeto consiste em analisar as principais ferramentas e métricas utilizadas na avaliação da maturação de projetos de manufatura enxuta em empresas brasileiras.

\section{Resultados e Discussão}

Inicialmente, foi realizada uma extensa revisão bibliográfica, e, com base nisso, foi elaborado um formulário contendo vinte e seis métricas selecionadas e dois critérios a serem avaliados em cada uma delas: grau de importância e de aplicação. Posteriormente, o questionário foi enviado para profissionais atuantes na área, previamente selecionados, obtendo-se quarenta e três respostas no total.

A partir disso, os dados coletados foram tratados estatisticamente através do software IBM SPSS Statiscs 22 utilizando-se das ferramentas Escalonamento Multidimensional (EMD) e Análise Fatorial Exploratória (AFE). Dessa forma, foi possível gerar os resultados da Tabela 1.

Pode-se observar, com base nesses resultados, que as métricas mais importantes são também as mais aplicadas e elas correspondem à redução do tempo geral da produção, redução dos estoques/ custos e aumento da produtividade visando o melhor atendimento aos consumidores.

DOI: 10.19146/pibic-2016-50845
Tabela 1. Resultados para critérios de importância e aplicação.

\begin{tabular}{|c|c|c|c|c|c|}
\hline \multicolumn{3}{|c|}{ IMPORTÂNCIA } & \multicolumn{3}{|c|}{ APLICAÇÃO } \\
\hline Ranking & Score & Métrica & Ranking & Score & Métrica \\
\hline 19 & 1,51473 & Redução nos lead time & 19 & 1,42599 & $\begin{array}{l}\text { Produtividade dos } \\
\text { funcionários }\end{array}$ \\
\hline 20 & 1,43675 & $\begin{array}{c}\text { Redução dos índices de } \\
\text { estoque }\end{array}$ & 20 & 1,26237 & $\begin{array}{c}\text { Redução no } n^{\circ} \text { de } \\
\text { reclamações }\end{array}$ \\
\hline 39 & 0,96066 & $\begin{array}{l}\text { Redução no } n^{\circ} \text { de } \\
\text { reclamações }\end{array}$ & 30 & 1,2586 & $\begin{array}{c}\text { Tempo de preparação de } \\
\text { células (setup) }\end{array}$ \\
\hline 49 & 0,94596 & $\begin{array}{l}\text { Redução do tempo de } \\
\text { espera industrial }\end{array}$ & 49 & 1,22659 & Redução nos lead time \\
\hline 50 & 0,94317 & $\begin{array}{c}\text { Melhorias no tempo de } \\
\text { valor agregado }\end{array}$ & 50 & 1,21809 & $\begin{array}{c}\text { Redução dos índices de } \\
\text { estoque }\end{array}$ \\
\hline 60 & 0,91946 & $\begin{array}{c}\text { Tempo de preparação de } \\
\text { células (setup) }\end{array}$ & 60 & 0,95595 & $\begin{array}{l}\text { Aumento da porcentagem } \\
\text { de entregas "on time" (\%) }\end{array}$ \\
\hline 79 & 0,86375 & $\begin{array}{l}\text { Aumento da porcentagem } \\
\text { de entregas "on time" }(\%)\end{array}$ & 70 & 0,87964 & $\begin{array}{l}\text { Redução no número de } \\
\text { scrap }\end{array}$ \\
\hline 89 & 0,84057 & $\begin{array}{l}\text { Produtividade dos } \\
\text { funcionários }\end{array}$ & 89 & 0,58672 & $\begin{array}{c}\text { Redução do tempo de } \\
\text { espera industrial }\end{array}$ \\
\hline 9o & 0,74115 & $\begin{array}{l}\text { Custo associado aos } \\
\text { estoques existentes }\end{array}$ & פำ & 0,48373 & Giro de estoque \\
\hline 109 & 0,53243 & $\begin{array}{c}\text { Redução no número de } \\
\text { scrap }\end{array}$ & 109 & 0,42923 & $\begin{array}{l}\text { Custo associado aos } \\
\text { estoques existentes }\end{array}$ \\
\hline
\end{tabular}

\section{Conclusões}

Após a análise dos resultados, concluiu-se que o lean é amplamente aplicado no Brasil em diversos segmentos industriais e que uma constante avaliação dessas métricas é importante para se acompanhar a evolução dessa estratégia de produção no cenário industrial brasileiro.

Os objetivos propostos foram cumpridos como esperado, gerando resultados que poderão ser de muita valia para os principais gestores da produção no Brasil.

\section{Agradecimentos}

Gostaria de agradecer ao Prof. Dr. Rosley Anholon pela ajuda e orientação. Agradecimento especial ao PIBIC e $\mathrm{CNPq}$ pelo apoio financeiro, sem o qual esse projeto não teria sido realizado.

\footnotetext{
Manimay Ghosh, (2012),"Lean manufacturing performance in Indian manufacturing plants", Journal of Manufacturing Technology Management, Vol. 24 Iss 1 pp. $113-122$
} 